\title{
Lobar Distribution of Lesion Volumes in Late-Life Depression: The Biomedical Informatics Research Network (BIRN)
}

\author{
James R MacFall*,', Warren D Taylor ${ }^{2}$, David E Rex ${ }^{3}$, Steve Pieper ${ }^{4}$, Martha E Payne ${ }^{2}$, Douglas R McQuoid ${ }^{2}$, \\ David C Steffens ${ }^{2}$, Ron Kikinis ${ }^{4}$, Arthur W Toga ${ }^{3}$ and K Ranga Rama Krishnan ${ }^{2}$ \\ 'Department of Radiology, Duke University Medical Center, Durham, NC, USA; 'Department of Psychiatry, Duke University Medical Center,

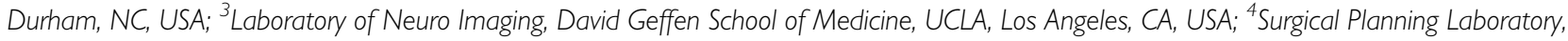 \\ Brigham and Women's Hospital, Boston, MA, USA
}

\begin{abstract}
White matter hyperintense lesions on T2-weighted images are associated with late-life depression. Little work has been carried out examining differences in lesion location between elderly individuals with and without depression. In contrast to previous studies examining total brain white matter lesion volume, this study examined lobar differences in white matter lesion volumes derived from brain magnetic resonance imaging. This study examined 49 subjects with a DSM-IV diagnosis of major depression and 50 comparison subjects without depression. All participants were age 60 years or older. White matter lesion volumes were measured in each hemisphere using a semiautomated segmentation process and localized to lobar regions using a lobar atlas created for this sample using the imaging tools provided by the Biomedical Informatics Research Network (BIRN). The lobar lesion volumes were compared against depression status. After controlling for age and hypertension, subjects with depression exhibited significantly greater total white matter lesion volume in both hemispheres and in both frontal lobes than did control subjects. Although a similar trend was observed in the parietal lobes, the difference did not reach a level of statistical significance. Models of the temporal and occipital lobes were not statistically significant. Older individuals with depression have greater white matter disease than healthy controls, predominantly in the frontal lobes. These changes are thought to disrupt neural circuits involved in mood regulation, thus increasing the risk of developing depression.
\end{abstract}

Neuropsychopharmacology (2006) 3 I, I 500- 1507. doi: I 0. I 038/sj.npp. I 300986; published online 7 December 2005

Keywords: depression; geriatrics; frontal lobe; MR imaging; hyperintense lesions; parietal lobe

\section{INTRODUCTION}

Depression in late life is associated with the occurrence of white matter hyperintense lesions (WMLs) detected on brain magnetic resonance imaging (MRI). These WMLs are bright regions, hyperintense on proton density (PD) and T2-weighted MRIs, seen in the parenchyma of the brain, and are associated with advanced age (Awad et al, 1986; Longstreth et al, 1996; Guttmann et al, 1998) and cardiovascular risk factors, particularly hypertension (Fazekas et al, 1988; Ylikoski et al, 1995; Longstreth et al, 1996; Liao et al, 1997; Veldink et al, 1998; Schmidt et al, 1999; Dufouil et al, 2001; Taylor et al, 2003a). Many reports associate hyperintense lesions with late-life depression. White and gray matter hyperintense lesions are more severe

*Correspondence: Dr JR MacFall, Department of Radiology, Duke University Medical Center, DUMC 3808, Durham, NC 27710, USA, Tel: + I 9196847808 , Fax: + I 9196847126 ,

E-mail: James.macfall@duke.edu

Received 29 June 2005; revised 6 October 2005; accepted 18 October 2005

Online publication: 27 October 2005 at http://www.acnp.org/citations/ Npp 10270505042 I/default.pdf in older depressed subjects than nondepressed subjects (Krishnan et al, 1988; Dolan et al, 1990; Fujikawa et al, 1993; Krishnan, 1993; Greenwald et al, 1996; Steffens et al, 1999; Kumar et al, 2000; Tupler et al, 2002; Taylor et al, 2005), and are more severe in late-onset than early-onset elderly depressed subjects (Figiel et al, 1991; Hickie et al, 1995; Salloway et al, 1996; Krishnan et al, 1997; Lavretsky et al, 1998; de Groot et al, 2000; Tupler et al, 2002). Increases in WML severity over time are additionally associated with new onset of depression (Lavretsky et al, 1999; Nebes et al, 2002) and poorer outcomes to antidepressant therapy (Simpson et al, 1997; O'Brien et al, 1998; Taylor et al, 2003c), although some have not found a relationship between WML severity and treatment outcomes (Salloway et al, 2002).

This body of work led to the development of the vascular depression hypothesis (Alexopoulos et al, 1997; Krishnan et al, 1997) and the more specific description of subcortical ischemic depression.(Krishnan et al, 2004) This hypothesis posits that WMLs represent cerebrovascular injury to the brain that may disrupt mood regulation, thus increasing the risk of developing depression. Thus, WMLs hypothetically contribute to the pathogenesis of depression by disrupting 
the fiber tracts that connect cortical and subcortical structures involved in mood regulation, such as disruption of frontostriatal circuits (Tekin and Cummings, 2002) or connections with limbic structures as described using functional imaging studies (Seminowicz et al, 2004), both of which are implicated as contributing to mood disorders.

Although the basis of this hypothesis is that WMLs related to depression must occur in specific areas, there is only limited research investigating this question. Several studies have noted that frontal WMLs are particularly associated with depression (Greenwald et al, 1998; Taylor et al, 2003b; Firbank et al, 2004), particularly WMLs occurring in the orbital frontal cortex (MacFall et al, 2001); this supports theories that frontal lobe regions are critical in mood regulation. Unfortunately, many of these studies did not examine other regions, such as the temporal or parietal lobes. Involvement of regions beyond the frontal lobe is a critical question as a recent large-scale population study associated depression with severe WML disease in the frontal and parietal lobes, but WML disease also extended into temporal and occipital regions (Artero et al, 2004). This finding contrasts with work using Statistical Parametric Mapping (SPM99) analyses that did consider the entire brain, and reported that differences in depression predominantly are in the frontal lobe (MacFall et al, 2001; Taylor et al, 2003b). The SPM voxel-based morphometry approach is useful, but has been criticized because of the extensive processing involved to create lesion density maps from high-resolution segmented images that identify the lesions.

There are alternative approaches to addressing this question. One such alternative is to localize lesions by measuring the lesion volume in each of the anatomically defined lobes of the brain. This can be carried out by creating a lobar atlas that is applied to the images of each subject; this sophisticated image processing capability is available in only a few research laboratories. A recent National Institutes of Health initiative know as the Biomedical Informatics Resource Network has begun to make such tools available to be used by a wider group of research laboratories who have medical imaging data that could benefit from such image processing tools.

In this paper, we report on the use of the Biomedical Informatics Research Network (BIRN) network to create brain lobar atlases for this imaging data and their use to report on the white matter lesion volumes within each lobe. We hypothesized that when compared with elderly control subjects, elderly subjects with depression would exhibit greater total WML volume, and based on hypotheses implicating the frontal lobe in the pathogenesis of depression, that the difference in WML volume between depressed and nondepressed subjects would be greatest in the frontal lobe. We further hypothesized that this difference would persist over a 2-year period.

\section{METHODS}

\section{Sample}

All subjects participated in the NIMH-sponsored Longitudinal Study of Late-Life Depression at Duke University
Medical Center. This study was approved by the Duke University Medical Center Institutional Review Board. After receiving an explanation of the study's purpose and procedures, subjects provided written informed consent.

Subjects were outpatients age 60 years or older with a diagnosis of nonpsychotic Major Depressive Disorder and a Center for Epidemiologic Studies-Depression Scale (Radloff, 1977) score $\geqslant 16$. They were recruited from clinical referrals. Exclusion criteria included (1) other major psychiatric illnesses; (2) history of substance abuse or dependence; (3) primary neurological illnesses, including stroke and dementia; (4) medical illnesses impairing cognitive function; (5) metal in the body precluding MRI; and (6) Mini-Mental State Examination (Folstein et al, 1975) score below 25. This group included subjects both with early-onset recurrent depression as well as those individuals with the first episode of depression occurring later in life.

Control subjects were age-matched community volunteers recruited from the Aging Center Subject Registry at Duke University. They had a nonfocal neurological examination, no self-report of neurologic or depressive illness, and no evidence of depression based on the Diagnostic Interview Schedule (Robins et al, 1981).

The sample for this study was a subset of 50 depressed subjects and 50 age-matched control subjects from the larger cohort; these subjects have been included in previous reports of larger samples examining cross-sectional differences between groups (Taylor et al, 2005) and longitudinal changes (Taylor et al, 2003a,c). Subjects were selected by the database manager based upon age and sex matching of those individuals with complete clinical and MRI assessment data for their baseline evaluation and the follow-up evaluation 2 years later.

The data were anonymized for subject privacy protection in accordance with HIPAA regulations. All image files and tabular data were converted to a standardized format, SAS export files for tabular data and DICOM for image data, and uploaded to the BIRN storage resource broker (SRB - the BIRN database) where they could be accessed by participating sites.

\section{Assessment of Medical Comorbidity}

Subjects completed a questionnaire that asked about the presence or absence of hypertension. These data were selfreport only and were derived from questions included in the NIMH Epidemiological Catchment Area program (Regier et al, 1984).

\section{Antidepressant Therapy}

During their participation in the study, depressed subjects were treated according to a treatment algorithm, the Duke STAGED Approach (Steffens et al, 2002). This algorithm mimics 'real-world' treatment options rather than a more rigid clinical trial design by accounting for past treatments and current severity. Never-treated subjects are initially prescribed a selective serotonin reuptake inhibitor (SSRI). If adequate doses of the SSRI do not bring sufficient response after 8-12 weeks, the recommendation is to switch to venlafaxine or augment with bupropion. Options after a 
continued, inadequate treatment response include tricyclic antidepressants and lithium augmentation. At each stage, doses are increased as tolerated or required, to the maximum approved dose. Electroconvulsive therapy is a treatment option at each algorithm level, dependent on subject severity, number of failed trials, and subject preference. Subjects were not routinely referred for psychotherapy, although some were already engaged in ongoing psychotherapy at study entry, while others were referred for individual and/or group psychotherapy, usually cognitive-behavioral psychotherapy.

\section{MRI Acquisition and Image Segmentation}

Subjects received brain MR imaging at baseline and then approximately 2 years later. At both instances, subjects were imaged with a $1.5 \mathrm{~T}$ whole-body, research-dedicated MRI system (Signa, GE Medical Systems, Milwaukee, WI) using a standard head (volumetric) radiofrequency coil. A dualecho fast spin-echo acquisition was obtained in the axial plane for morphometry. The pulse sequence parameters were $\mathrm{TR}=4000 \mathrm{~ms}, \mathrm{TE}=30,135 \mathrm{~ms}, 32 \mathrm{kHz},( \pm 16 \mathrm{kHz})$ full-imaging bandwidth, echo train length $=16$, a $256 \times 256$ matrix, contiguous $3 \mathrm{~mm}$ section thickness, one excitation, and a $20 \mathrm{~cm}$ field of view.

The volumes of lesions, gray matter, white matter, and CSF were determined through the use of semiautomated segmentation and volume measurement computer programs in the Neuropsychiatric Imaging Research Laboratory at Duke University Medical Center (Byrum et al, 1996; Payne et al, 2002). Periventricular and deep white matter lesions were separately identified, but were combined in the results reported here. As this study specifically aimed to examine differences in WML volume, subcortical gray matter lesions were not included in the analyses. Additionally, due to image processing methods, brainstem lesions were not included.

All image analysts received extensive training. Reliability was established by repeated measurements on multiple MR scans before analysts processed study data. Intraclass correlation coefficients were left cerebral gray matter lesions $=0.995$; right cerebral gray matter lesions $=0.996$; left cerebral white matter lesions $=0.988$; and right cerebral white matter lesions $=0.994$.

\section{Brain Template and Lobar Atlas Creation}

Assignment of a given brain region to left or right frontal, temporal, parietal, or occipital lobes was accomplished using BIRN-enabled computer programs. A 'template' image that is essentially an average $\mathrm{PD}$ brain image for this population was first created using previously described methods provided to the BIRN by the Laboratory of Neuro Imaging (LONI), University of California, Los Angeles, CA (Rex et al, 2003). Similarly a T2-weighted template image was also created. Figure 1 shows the PD template.

The lobar atlas was created from this template via manual delineation (DER) of the subject atlas space utilizing intensity information from the average PD and average T2 volumes. The landmarks used were similar to those of the ICBM305 anatomic delineation (Evans et al, 1996) and are

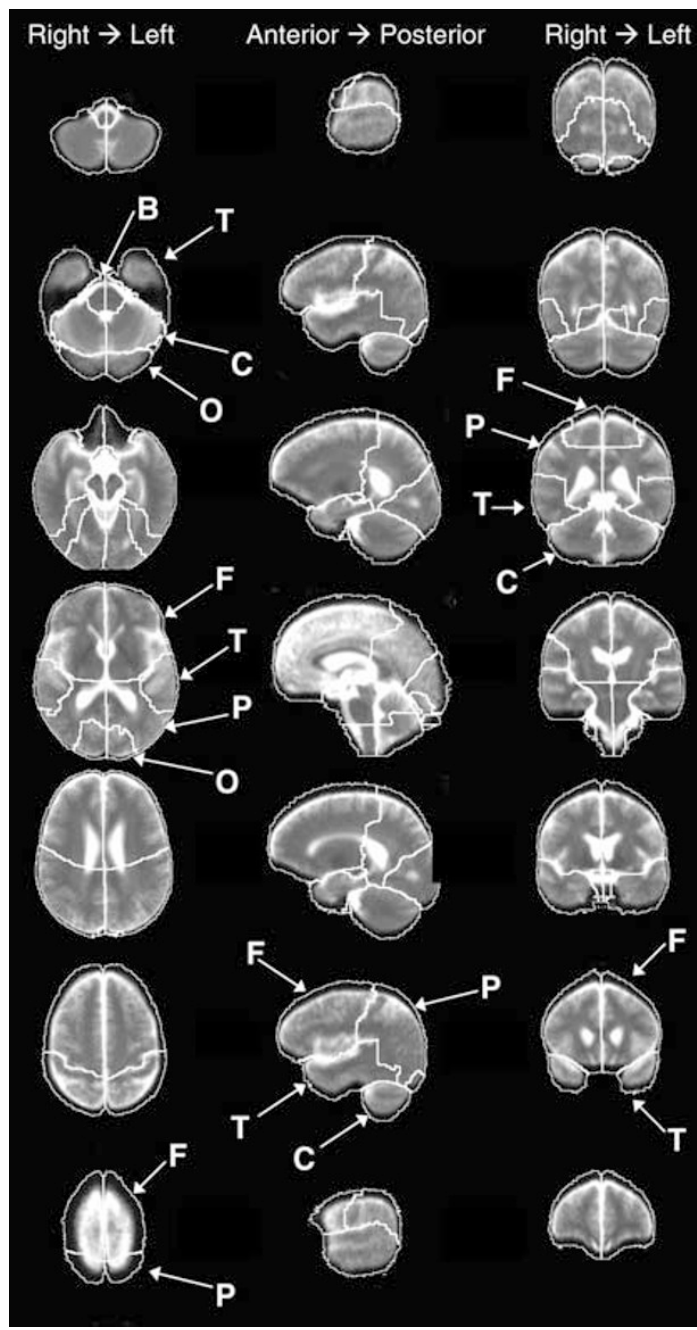

Figure I Diagram of the lobar atlas. The lobes are demarked by lines and the regions are labeled accordingly: $F=$ frontal lobe; $P=$ parietal lobe; $\mathrm{O}=$ occipital lobe; $\mathrm{T}=$ temporal lobe; $\mathrm{C}=$ cerebellum

as found for the LONI sulcal delineation protocol (Luders et al, 2003; http://www.loni.ucla.edu/ad/AD_protocol/sulcal. html). An illustration of the atlas, superimposed on the template brain, is shown in Figure 1. Note that the atlas is somewhat larger than the template to avoid cutting off sections of the brain or CSF near the surface.

Study subjects' images had the skull removed for registration purposes using an automated skull-stripping method (Rex et al, 2004). The T2 template was aligned to each skull-stripped depressed and control subject via a fifth-order polynomial nonlinear alignment (Woods et al, 1998). The associated lobar atlas was then transformed to each subject using a nearest-neighbor interpolation, preserving the borders of the labeling, in order to define each lobe of each subject for regional analyses. This was performed in an automated manner utilizing the LONI Pipeline Processing Environment (Rex et al, 2003).

To calculate the lobar lesion volumes for each subject, voxels containing lesion (in the untransformed, original coordinate system) were classified as belonging to a given lobe using the atlas that was transformed to the subject's 
original coordinate system. Then, the lesion volume for each lobe was calculated by summing up the number of such voxels in each lobe and multiplying by the (common) voxel volume.

\section{Analytic Strategy}

All analyses were completed using SAS (version 8.2; Cary, NC). Summary statistics for each group were derived for demographic and clinical variables, including MRI results. General linear models were created for the analysis of crosssectional data at both baseline and follow-up; they were determined to reach statistical significance if the overall model had a $p$-value $<0.05$. These models examined lesion volume in each region as the dependent variable, with depression status, age, and the presence or absence of hypertension as independent variables. From these models, the least-squares mean of the WML volume in each region was calculated for both depressed and control subjects. As we have previously demonstrated that age and presence of hypertension are independently related to WML volume (Taylor et al, 2005), this approach provides an adjusted difference between the depressed and nondepressed groups, so may be more accurate than a report of unadjusted observed means. However, unadjusted observed means were calculated for lesion volumes in brain regions where the overall models were not statistically significant, and differences examined using Satterthwaite $t$-tests due to unequal variances.

A similar method was used for examining differences in change in WML volume between the two scans. These general linear models examined change in WML volume as the dependent variable, with depression status, age, and the presence or absence of hypertension as independent variables. The least-squares mean of the change in WML volume in each region was calculated for both depressed and control subjects. This issue was also examined using mixed measures models, where WML volume was the dependent variable, and depression status, time, age, and hypertension were independent variables. These models also included a depression status (group) by time interaction term.

\section{RESULTS}

\section{Demographic and Clinical Differences}

We examined 49 depressed and 50 control subjects; one depressed subject's MRI data could not be analyzed due to a nonconforming protocol. There were no significant differences between groups in mean age (depressed: 68.2 years, range $=60-82$ years, $\mathrm{SD}=6.4$; control: 68.6 years, range $=60-81$ years, $\mathrm{SD}=5.7 ; 97 \mathrm{df}, t=0.37, p=0.709$ ) or sex (depressed: 63.3\% female; control: 62.0\% female; $\left.\chi^{2}=0.02, p=0.897\right)$. In the depressed group, one was Asian-Americans, three were African-Americans, and 46 Caucasians; in the control group, six were African-Americans and 44 Caucasians. There was no significant difference between groups in the ratio of minorities to Caucasians (Fisher's exact, $p=0.487$ ). The control group overall had a significantly higher mean level of education (control: 15.4 years, range $=12-17$ years; depressed $=14.3$ years, range $=$ 8-17 years; $97 \mathrm{df}, t=2.56, p=0.010$ ).

Hypertension was more commonly reported in the depressed (in 24 of 49 subjects) than the control group (eight of 50 subjects; $\chi^{2}=12.30, p=0.0005$ ). Depressed subjects had a mean age of depression onset of 40.0 years (range $=7-71$ years; $\mathrm{SD}=18.0$ years) and a depression severity, measured using the Montgomery-Asburg Depression Rating Scale (Montgomery and Asberg, 1979), of 27.1 (range $=16-53 ; \mathrm{SD}=7.8$ )

\section{MR Hyperintense Lesion Volume Differences}

All baseline lesion measurements found greater lesion volumes in depressed than control subjects (Table 1). General linear models tested for differences between groups while accounting for age and hypertension. Depression was associated with significantly greater WML volumes in total brain volume measurements, and all frontal lobe measures. There was also a statistical trend that did not reach a level of significance that depressed subjects exhibited greater WML volumes in the total and right parietal lobe. Age was significantly $(p<0.05)$ associated with greater WML volumes in total brain, frontal, and parietal lobe analyses.

Table I Initial White Matter Lesion Volume by Lobe: Association with Depression Status

\begin{tabular}{|c|c|c|c|c|c|c|}
\hline & Depressed (SE) & Control (SE) & Mean difference & Parameter estimate & t-value & $p$-value \\
\hline Total brain WMH lesion volume & $6.11(0.90)$ & $3.09(1.02)$ & 3.02 & 1.36 & 2.23 & 0.0283 \\
\hline Left hemisphere WMH lesion volume & $2.95(0.41)$ & $1.63(0.47)$ & 1.32 & 0.62 & 2.12 & 0.0363 \\
\hline Right hemisphere WMH lesion volume & $3.16(0.50)$ & $1.46(0.56)$ & 1.70 & 0.75 & 2.27 & 0.0254 \\
\hline Total frontal lobe WMH lesion volume & $4.17(0.46)$ & $2.37(0.52)$ & 1.80 & 0.69 & 2.63 & 0.0101 \\
\hline Left frontal lobe WMH lesion volume & $2.02(0.21)$ & $1.22(0.24)$ & 0.80 & 0.31 & 2.55 & 0.0123 \\
\hline Total parietal lobe WMH lesion volume & $1.87(0.46)$ & $0.74(0.45)$ & 1.13 & 0.70 & 1.62 & 0.1084 \\
\hline Left parietal lobe WMH lesion volume & $0.91(0.21)$ & $0.43(0.21)$ & 0.48 & 0.33 & 1.47 & 0.1451 \\
\hline Right parietal lobe WMH lesion volume & $0.96(0.25)$ & $0.31(0.28)$ & 0.65 & 0.37 & 1.76 & 0.0814 \\
\hline
\end{tabular}

WMH volumes (in $\mathrm{ml}$ ) displayed are least-squares mean volumes, from models controlling for age, depression status, and hypertension; standard error for these volumes are reported rather than standard deviation as they were derived from these models. The statistical parameter estimate, standard error (SE), $t$-value, and $p$ value report the influence of depression on WMH lesion volume in general linear models, which also include age and hypertension and independent variables. 
Hypertension was not associated with lesion volume in any analysis.

The least-squares mean WML volumes in the follow-up assessment increased from baseline, and depressed subjects continued to exhibit greater lesion volumes than control subjects (Table 2). Similar to the analysis of baseline data, after controlling for age and hypertension, depression was significantly associated with greater WML volumes in total brain and frontal measures. The statistical trend for differences in the total and right parietal lobe also remained. Likewise, age continued to be associated with greater total, frontal, and parietal WML volume, while hypertension was not associated with WML volume in any analysis.

Analyses of occipital and temporal lobe WML volumes were also attempted. These models failed to reach an overall level of statistical significance using either the baseline or follow-up data. Unadjusted means and univariate analyses demonstrate that depressed subjects exhibited greater WML volumes in these lobes, although the differences between groups do not reach a level of statistical significance. In the baseline analyses of the occipital lobe, depressed subjects exhibited a mean WML volume of $0.0381 \mathrm{ml}(\mathrm{SD}=0.179)$, while control subjects exhibited a mean WML volume of $0.0008 \mathrm{ml} \mathrm{(SD=0.004;} \mathrm{Satterthwaite} t=1.42,48 \mathrm{df}$, $p=0.161)$. In follow-up scan analyses of the occipital lobe, depressed subjects exhibited a mean WML volume of $0.0513 \mathrm{ml}(\mathrm{SD}=0.248)$, while control subjects exhibited a mean WML volume of $0.0132 \mathrm{ml}(\mathrm{SD}=0.179$; Satterthwaite $t=0.95,53.2 \mathrm{df}, p=0.348)$. In baseline analyses of the temporal lobe, depressed subjects exhibited a mean WML volume of $0.018 \mathrm{ml}(\mathrm{SD}=0.084)$, while control subjects exhibited a mean WML volume of $0.002 \mathrm{ml}(\mathrm{SD}=0.006$; Satterthwaite $t=1.29,48.5 \mathrm{df}, p=0.204)$. In follow-up scan analyses of the temporal lobe, depressed subjects exhibited a mean WML volume of $0.057 \mathrm{ml}(\mathrm{SD}=0.273)$, while control subjects exhibited a mean WML volume of $0.005 \mathrm{ml}$ $(\mathrm{SD}=0.014$, Satterthwaite $t=1.35,48.3 \mathrm{df}, p=0.184)$.

\section{Analysis of WMH Lesion Volume Change between MRI Scans}

There was a mean time of 734 days $(S D=23.6$; minimum $=680$ days, maximum $=806$ days) between MRI scans for the entire group. There was no statistically significant difference in time between scans and between the depressed (mean 730 days, $\mathrm{SD}=27.5$ ) and control groups (mean 737 days, $\mathrm{SD}=18.5$; Satterthwaite $t$-test, $83.9 \mathrm{df}, \quad t=1.67$, $p=0.0982$ ).

After controlling for age and hypertension, depressed subjects exhibited larger least-squares mean change in WMH lesion volume over the study period than did control subjects, but this did not reach a level of statistical significance (Table 3). Age, but not hypertension, was positively associated with WMH lesion volume change in total, frontal, and parietal measures. In mixed measures models, no WMH lesion volume measure exhibited a statistically significant group by time interaction.

\section{DISCUSSION}

The main finding was that depressed subjects exhibited greater white matter lesion volumes in the frontal lobe than do control subjects. This finding remained statistically significant even after controlling for age and reports of hypertension. These findings were consistent between the baseline and follow-up scans. We did not detect any statistically significant change in WML volume in any lobe over the study period between the two groups.

Our finding of greater WML volumes in the frontal lobe is concordant with previous studies. Numerous other reports have also found greater total WML volumes in elderly depressed subjects (Krishnan et al, 1988; Dolan et al, 1990; Fujikawa et al, 1993; Krishnan, 1993; Greenwald et al, 1996; Steffens et al, 1999; Kumar et al, 2000; Tupler et al, 2002), but few of these studies examined the location of WMLs. Using an objective method of quantifying WML volume within each lobe, we have confirmed reports (Greenwald et al, 1998; MacFall et al, 2001; Taylor et al, 2003b; Firbank et al, 2004) that the preponderance of WMLs that are different between depressed and control populations occur in the frontal lobe. Although others have proposed there may be differences between groups in other lobes, we did not confirm this finding (Artero et al, 2004). Our current approach has several advantages over that used in previous studies, including a larger sample, objective WML volume

Table 2 Follow-Up White Matter Lesion Volumes by Lobe: Association with Depression Status

\begin{tabular}{|c|c|c|c|c|c|c|}
\hline & Depressed (SE) & Control (SE) & Mean difference & Parameter estimate & t-value & $p$-value \\
\hline Total brain WMH lesion volume & $7.52(1.10)$ & $3.82(1.25)$ & 3.70 & 3.70 & 2.23 & 0.0280 \\
\hline Left hemisphere WMH lesion volume & $3.64(0.51)$ & $2.03(0.57)$ & 1.61 & 1.61 & 2.11 & 0.0375 \\
\hline Right hemisphere WMH lesion volume & $3.87(0.60)$ & $1.79(0.68)$ & 2.08 & 2.08 & 2.29 & 0.0242 \\
\hline Total frontal lobe WMH lesion volume & $4.95(0.56)$ & $2.86(0.63)$ & 2.09 & 2.09 & 2.49 & 0.0145 \\
\hline Left frontal lobe WMH lesion volume & $2.38(0.25)$ & $1.49(0.29)$ & 0.89 & 0.89 & 2.34 & 0.0214 \\
\hline Left parietal lobe WMH lesion volume & $1.22(0.26)$ & $0.54(0.30)$ & 0.68 & 0.67 & 1.69 & 0.0938 \\
\hline Right parietal lobe WMH lesion volume & $1.25(0.29)$ & $0.43(0.33)$ & 0.82 & 0.82 & 1.86 & 0.0653 \\
\hline
\end{tabular}

WMH volumes displayed are least-squares mean volumes, from models controlling for age, depression status, and hypertension; standard error for these volumes are reported rather than standard deviation as they were derived from these models. The statistical parameter estimate, standard error (SE), $t$-value, and $p$-value report the influence of depression on WMH lesion volume in general linear models, which also include age and hypertension and independent variables. Models of occipital and temporal WML volumes are not included as the models did not reach statistical significance. 
Table 3 Change Over Time in WMH Lesion Volume between Groups

\begin{tabular}{|c|c|c|c|c|c|c|}
\hline & Depressed (SE) & Control (SE) & Mean difference & Parameter estimate & t-value & $p$-value \\
\hline Total brain WMH lesion volume & ।.4I (0.37) & $0.73(0.42)$ & 0.68 & 0.56 & 1.21 & 0.2291 \\
\hline Left hemisphere WMH lesion volume & $0.69(0.19)$ & $0.40(0.22)$ & 0.29 & 0.28 & 1.02 & 0.3093 \\
\hline Right hemisphere WMH lesion volume & $0.7 \mid(0.19)$ & $0.33(0.2)$ & 0.38 & 0.28 & 1.36 & 0.1779 \\
\hline Total frontal lobe WMH lesion volume & $0.78(0.24)$ & $0.49(0.27)$ & 0.29 & 0.36 & 0.81 & 0.4217 \\
\hline Left frontal lobe WMH lesion volume & $0.36(0.12)$ & $0.27(0.14)$ & 0.09 & 0.18 & 0.50 & 0.6168 \\
\hline Total parietal lobe WMH lesion volume & $0.60(0.14)$ & $0.25(0.16)$ & 0.35 & 0.22 & 1.65 & 0.1027 \\
\hline Left parietal lobe WMH lesion volume & $0.32(0.08)$ & $0.13(0.09)$ & 0.19 & 0.12 & 1.60 & 0.1134 \\
\hline Right parietal lobe WMH lesion volume & $0.28(0.07)$ & $0.12(0.08)$ & 0.16 & 0.10 & 1.61 & 0.1102 \\
\hline
\end{tabular}

WMH volumes displayed are least-squares mean volumes of the difference between scans, derived from models controlling for age, depression status, and hypertension; standard error for these volumes are reported rather than standard deviation as they were derived from these models. The statistical parameter estimate, standard error (SE), $t$-value, and $p$-value report the influence of depression on WMH lesion volume in general linear models, which also include age and hypertension and independent variables. Models of occipital and temporal WML volumes are not included as the models did not reach statistical significance.

measurements, and using an atlas-defined definition of lobes. These findings also support the body of evidence implicating frontal lobe regions as being particularly important in the pathogenesis of depression.

We did not demonstrate a statistically significant difference in the change of WML volumes between groups over the study period. However, our point estimates of volume change in the total brain, and frontal and parietal lobes were persistently higher in the depressed group. The inability to demonstrate a statistically significant difference was likely due to a relatively short follow-up period and a sample size insufficient to detect a difference over the study period; however, the change we report is comparable to that found in other longitudinal studies investigating either total (Taylor et al, 2003a) or deep white matter lesion volume (Cook et al, 2004). Other studies have demonstrated that WMLs do increase in severity and volume over time, and that greater change is associated with depression outcomes (Nebes et al, 2002; Taylor et al, 2003c).

Although there was a trend that depressed subjects may also exhibit greater WML volumes in the parietal lobe, this did not reach a level of statistical significance. Although this may reflect that WMLs in the parietal lobe do not contribute to the pathogenesis of depression, the trend we observed may instead indicate that this study was underpowered to detect a real difference between groups. Although some have associated parietal WMLs with depression (Artero et al, 2004), others have not found such an association (Firbank et al, 2004). However, given reports of reductions in parietal gray matter in depression (Ballmaier et al, 2004), and an association between parietal lobe volume and cognitive deficits in depression (Simpson et al, 2001), more research is needed into the role of the parietal lobe in depression.

Our models of WML volumes in the occipital and temporal lobes did not reach levels of statistical significance. This may be due to the same reasons discussed above, or due to only a small number of subjects exhibiting WMLs in these lobes. However, other possibilities exist, such as how factors other than age, depression, or hypertension may contribute to their development.
Although large compared with other imaging studies, sample size is a limitation of the study, particularly when considering the longitudinal analyses. Additionally, other studies have used FLAIR (fluid-attenuated inversion recovery) MR imaging to detect WMLs, which were not available for use when the presently reported data was gathered. While WMLs were detected reliably in this study, other studies that used FLAIR may have greater sensitivity to smaller lesions and different criteria for classification of WML. Another limitation is our measure of hypertension, which was a simple self-report of the presence or absence of a diagnosis; such an approach may underestimate true disease prevalence, and provides no objective measure of disease severity. This limitation, along with the smaller sample size, may have contributed to why we did not find an association between hypertension and WML volume, which may be a false-negative result as it is different from studies examining larger samples (Taylor et al, 2005). Finally, we did not examine other potential risk factors such as smoking or hyperlipidemia, although these may not contribute to lesion development (Uehara et al, 1999; Saitoh et al, 2002). Of note, questions of medical comorbidity are particularly important for questions of etiology, or when investigating overall differences between groups. When considering issues of WML volume within specific locations, they may be less important. However, given that depressed elders may have higher levels of medical comorbidity than do nondepressed elderly samples (Taylor et al, 2004), it is important to adjust for this difference, and future studies should have more comprehensive and objective measures of medical burden.

Another important avenue for future research is further investigation of lobar change in WML volume over time, and how it may be related to type and intensity of antidepressant therapy. Over the 2-year study period, depressed subjects generally had greater change in WML volume in the frontal and parietal lobes than did control subjects, although likely due to the small sample size, this did not reach a level of statistical significance. In addition to including comprehensive measures of medical burden, adequacy of medical treatment should be considered as 
well as type and intensity of antidepressant treatment. Any of these factors may hypothetically affect WML progression. This is an important avenue for further research, particularly when combined with advanced MR techniques, such as diffusion tensor imaging fiber tract mapping, which can better describe neural connectivity and identify critical sites where lesion development may directly contribute to the pathogenesis of depression.

\section{ACKNOWLEDGEMENTS}

We acknowledge Denise Fetzer and Brian Boyd of the Duke Neuropsychiatric Imaging Research Laboratory for image analysis and computer processing and Syam Gadde of the Duke Brain Imaging and Analysis Center for help with data upload to the BIRN. This study was supported by $\mathrm{NIH}$ Grants from the Silvio Conte Center P50 MH60451, R01 MH54846, the morphometry BIRN U24RR021382, K24 MH70027, P41 RR13218, and K23 MH65939, P41 RR013642, and the NIH Roadmap Initiative for Bioinformatics and Computational Biology, U54 RR021813, funded by the NCRR, NCBC, and NIGMS. This study was also financially supported by M01 RR00030.

\section{REFERENCES}

Alexopoulos GS, Meyers BS, Young RC, Campbell S, Silbersweig D, Charlson M (1997). Vascular depression' hypothesis. Arch Gen Psychiatry 54: 915-922.

Artero S, Tiemeier H, Prins ND, Sabatier R, Breteler MMB, Ritchie $\mathrm{K}$ (2004). Neuroanatomical localisation and clinical correlates of white matter lesions in the elderly. J Neurol Neurosurg Psychiatry 75: 1304-1308.

Awad IA, Spetzler RF, Hodak JA, Awad CA, Carey R (1986). Incidental subcortical lesions identified on magnetic resonance imaging in the elderly. I. Correlation with age and cerebrovascular risk factors. Stroke 17: 1084-1089.

Ballmaier M, Kumar A, Thompson PM, Narr KL, Lavretsky H, Estanol L et al (2004). Localizing gray matter deficits in lateonset depression using computational cortical pattern matching methods. Am J Psychiatry 161: 2091-2099.

Byrum CE, MacFall JR, Charles HC, Chitilla VR, Boyko OB, Upchurch L et al (1996). Accuracy and reproducibility of brain and tissue volumes using a magnetic resonance segmentation method. Psychiatry Res 67: 215-234.

Cook IA, Leuchter AF, Morgan ML, Dunkin JJ, Witte E, David S et al (2004). Longitudinal progression of subclinical structural brain disease in normal aging. Am J Geriatr Psychiatry 12: 190-200.

de Groot JC, de Leeuw F, Oudkerk M, Hofman A, Jolles J, Breteler MMB (2000). Cerebral white matter lesions and depressive symptoms in elderly adults. Arch Gen Psychiatry 57: 1071-1076.

Dolan RJ, Poynton AM, Bridges PK, Trimble MR (1990). Altered magnetic resonance white-matter T1 values in patients with affective disorder. Br J Psychiatry 157: 107-110.

Dufouil C, de Kersaint-Gilly A, Besancon V, Levy C, Auffray E, Brunnereau L et al (2001). Longitudinal study of blood pressure and white matter hyperintensities. Neurology 56: 921-926.

Evans AC, Collins DL, Holmes CJ (1996). Automatic 3D Regional MRI Segmentation and Statistical Probabilistic Anatomic Maps. Academic Press: New York.

Fazekas F, Niederkor K, Schmidt R, Offenbacher H, Honner S, Bertha $G$ et al (1988). White matter signal abnormalities in normal individuals: correlation with carotid ultrasonagraphy, cerebral blood flow measurements, and cerebrovascular risk factors. Stroke 19: 1285-1288.

Figiel GS, Krishnan KRR, Doraiswamy PM, Rao VP, Nemeroff CB, Boyko OB (1991). Subcortical hyperintensities on brain magnetic resonance imaging: a comparison between late age onset and early onset elderly depressed subjects. Neurobiol Aging 12: 245-247.

Firbank MJ, Lloyd AJ, Ferrier N, O’Brien JT (2004). A volumetric study of MRI signal hyperintensities in late-life depression. $A m \mathrm{~J}$ Geriatr Psychiatry 12: 606-612.

Folstein MF, Folstein SE, McHugh PR (1975). 'Mini-mental state' a practical method for grading the cognitive state of patients for the clinician. J Psychiatr Res 12: 189-198.

Fujikawa T, Yamawaki S, Touhouda Y (1993). Incidence of silent cerebral infarction in patients with major depression. Stroke 24: 1631-1634.

Greenwald BS, Kramer-Ginsberg E, Krishnan KRR, Ashtari M, Auerbach C, Patel M (1998). Neuroanatomic localization of magnetic resonance imaging signal hyperintensities in geriatric depression. Stroke 29: 613-617.

Greenwald BS, Kramer-Ginsberg E, Krishnan KRR, Ashtari M, Aupperle PM, Patel M (1996). MRI signal hyperintensities in geriatric depression. Am J Psychiatry 153: 1212-1215.

Guttmann CRG, Jolesz FA, Kikinis R, Killiany RJ, Moss MB, Sandor $\mathrm{T}$ et al (1998). White matter changes with normal aging. Neurology 50: 972-978.

Hickie I, Scott E, Mitchell P, Wilhelm K, Austin MP, Bennett B (1995). Subcortical hyperintensities on magnetic resonance imaging: clinical correlates and prognostic significance in patients with severe depression. Biol Psychiatry 37: 151-160.

Krishnan KRR (1993). Neuroanatomic substrates of depression in the elderly. J Geriatr Psychiatry Neurol 6: 39-58.

Krishnan KRR, Goli V, Ellinwood EH, France RD, Blazer DZ, Nemeroff CB (1988). Leukoencephalopathy in patients diagnosed as major depressive. Biol Psychiatry 23: 519-522.

Krishnan KRR, Hays JC, Blazer DG (1997). MRI-defined vascular depression. Am J Psychiatry 154: 497-501.

Krishnan KRR, Tayor WD, McQuoid DR, MacFall JR, Payne ME, Provenzale JM et al (2004). Clinical characteristics of magnetic resonance imaging-defined subcortical ischemic depression. Biol Psychiatry 55: 390-397.

Kumar A, Bilker W, Jin Z, Udupa J (2000). Atrophy and high intensity lesions: complementary neurobiological mechanisms in late-life depression. Neuropsychopharmacology 22: 264-274.

Lavretsky H, Lesser IM, Wohl M, Miller BL (1998). Relationship of age, age at onset, and sex to depression in older adults. Am J Geriatr Psychiatry 6: 248-256.

Lavretsky H, Lesser IM, Wohl M, Miller BL, Mehringer CM (1999). Clinical and neuroradiologic features associated with chronicity in late-life depression. Am J Geriatr Psychiatry 7: 309-316.

Liao D, Cooper L, Cai J, Bryan N, Burke G, Shahar E et al (1997). The prevalence and severity of white matter lesions, their relationship with age, ethnicity, gender, and cardiovascular disease risk factors: the ARIC Study. Neuroepidemiology 16: 149-162.

Longstreth WTJ, Manolio TA, Arnold A, Burke GL, Bryan N, Jungreis CA et al (1996). Clinical correlates of white matter findings on cranial magnetic resonance imaging of 3301 elderly people: the cardiovascular health study. Stroke 27: 1274-1282.

Luders E, Rex DE, Woods RP, Jancke L, Thompson PM, Mazziotta JC et al (2003). Relationships between sulcal asymmetries and corpus callosum size: gender and handedness effects. Cereb Cortex 13: 1084-1093.

MacFall JR, Payne ME, Provenzale JM, Krishnan KRR (2001). Medial orbital frontal lesions in late-onset depression. Biol Psychiatry 49: 803-806.

Montgomery SA, Asberg M (1979). A new depression scale designed to be sensitive to change. Br J Psychiatry 134: 382-389. 
Nebes RD, Reynolds CF, Boada F, Meltzer CC, Fukui MB, Saxton J et al (2002). Longitudinal increase in the volume of white matter hyperintensities in late-onset depression. Int J Geriatr Psychiatry 17: 526-530.

O'Brien J, Ames D, Chiu E, Schweitzer I, Desmond P, Tress B (1998). Severe deep white matter lesions and outcome in elderly patients with major depressive disorder: follow up study. $B M J$ 317: 982-984.

Payne ME, Fetzer DL, MacFall JR, Provenzale JM, Byrum CE, Krishnan KRR (2002). Development of a semi-automated method for quantification of MRI gray and white matter lesions in geriatric subjects. Psychiatry Res 115: 63-77.

Radloff LS (1977). The CES-D scale: A self-report depression scale for research in the general population. Applied Psychological Measurement 1: 385-401.

Regier DA, Myers JK, Kramer M, Robins LN, Blazer DG, Hough RL et al (1984). The NIMH epidemiologic catchment area program: historical context, major objectives, and study population characteristics. Arch Gen Psychiatry 41: 934-941.

Rex DE, Ma JQ, Toga AW (2003). The LONI pipeline processing environment. Neuroimage 19: 1033-1048.

Rex DE, Shattuck DW, Woods RP, Narr KL, Luders E, Rehm K et al (2004). A meta-algorithm for brain extraction in MRI. Neuroimage 23: 625-637.

Robins LN, Helzer JE, Croughan J, Ratcliff KS (1981). National institute of mental health diagnostic interview schedule. Its history, characteristics, and validity. Arch Gen Psychiatry 38: 381-389.

Saitoh T, Daimon M, Eguchi H, Hosoya T, Kawanami T, Kurita K et al (2002). Type 2 diabetes is not a risk factor for asymptomatic ischemic brain lesion - the Funagata study. Intern Med 41: 351-356.

Salloway S, Boyle PA, Correia S, Malloy PF, Cahn-Weiner DA, Schneider L et al (2002). The relationship of MRI subcortical hyperintensities to treatment response in a trial of sertraline in geriatric depressed outpatients. Am J Geriatr Psychiatry 10: 107-111.

Salloway S, Malloy P, Kohn R, Gillard E, Duffy J, Rogg J et al (1996). MRI and neuropsychological differences in early- and late-life-onset geriatric depression. Neurology 46: 1567-1574.

Schmidt R, Fazekas F, Kapeller P, Schimdt H, Hartung H-P (1999). MRI white matter hyperintensities: three-year follow-up of the Austrian Stroke Prevention Study. Neurology 53: 132-139.

Seminowicz DA, Mayberg HS, McIntosh AR, Goldapple K, Kennedy S, Segal Z et al (2004). Limbic-frontal circuitry in major depression: a path modeling metanalysis. Neuroimage 22: 409-418.

Simpson SW, Baldwin RC, Burns A, Jackson A (2001). Regional cerebral volume measurements in late-life depression: relationship to clinical correlates, neuropsychological impairment and response to treatment. Int J Geriatr Psychiatry 16: 469-476.
Simpson SW, Jackson A, Baldwin RC, Burns A (1997). Subcortical hyperintensities in late-life depression: acute response to treatment and neuropsychological impairment. Int Psychogeriatr 9: $257-275$.

Steffens DC, Helms MJ, Krishnan KRR, Burke GL (1999). Cerebrovascular disease and depression symptoms in the cardiovascular health study. Stroke 30: 2159-2166.

Steffens DC, McQuoid DR, Krishnan KRR (2002). The duke somatic treatment algorithm for geriatric depression (STAGED) approach. Psychopharmacol Bull 36: 58-68.

Taylor WD, MacFall JR, Payne ME, McQuoid DR, Steffens DC, Provenzale JM et al (2005). Greater MRI lesion volumes in elderly depressed subjects than in control subjects. Psychiatry Res 139: 1-7.

Taylor WD, MacFall JR, Provenzale JM, Payne ME, McQuoid DR, Steffens DC et al (2003a). Serial MR imaging of hyperintense white matter lesion volumes in elderly subjects: correlation with vascular risk factors. Am J Roentgenol 181: 571-576.

Taylor WD, MacFall JR, Steffens DC, Payne ME, Provenzale JM, Krishnan KRR (2003b). Localization of age-associated white matter hyperintensities in late-life depression. Prog Neuropsychopharmacol Biol Psychiatry 27: 539-544.

Taylor WD, McQuoid DR, Krishnan KR (2004). Medical comorbidity in late-life depression. Int $J$ Geriatr Psychiatry 19: 935-943.

Taylor WD, Steffens DC, MacFall JR, McQuoid DR, Payne ME, Provenzale JM et al (2003c). White matter hyperintensity progression and late-life depression outcomes. Arch Gen Psychiatry 60: 1090-1096.

Tekin S, Cummings JL (2002). Frontal-subcortical neuronal circuits and clinical neuropsychiatry an update. J Psychosom Res 53: 647-654.

Tupler LA, Krishnan KRR, McDonald WM, Dombeck CB, D'Souza S, Steffens DC (2002). Anatomic location and laterality of MRI signal hyperintensities in late-life depression. J Psychosom Res 53: 665-676.

Uehara T, Tabuchi M, Mori E (1999). Risk factors for silent cerebral infarcts in subcortical white matter and basal ganglia. Stroke 30: 378-382.

Veldink JH, Scheltens P, Jonker C, Launer LJ (1998). Progression of cerebral white matter hyperintensities on MRI is related to diastolic blood pressure. Neurology 51: 319-320.

Woods RP, Grafton ST, Holmes CJ, Cherry SR, Mazziotta JC (1998). Automated image registration: I. General methods and intrasubject, intramodality validation. J Comput Assit Tomogr 22: $139-152$

Ylikoski A, Erkinjuntti T, Raininko R, Sarna S, Sulkava R, Tilvis R (1995). White matter hyperintensities on MRI in the neurologically nondiseased elderly: analysis of cohorts of consecutive subjects aged 55-85 years living at home. Stroke 26: 1171-1177. 